\title{
EGFR NP_005219.2:p.C797A
}

National Cancer Institute

\section{Source}

National Cancer Institute. EGFR NP 005219.2:p.C797A. NCI Thesaurus. Code C147012.

A change in the amino acid residue at position 797 in the epidermal growth factor receptor protein where cysteine has been replaced by alanine. 